\title{
Sleep Quality and Fatigue Level of Patients with Coronary Angiography
}

\author{
Tugba Onegi ${ }^{1}\left(D\right.$, Dilek Efe Arslan ${ }^{2}$ \\ ${ }^{1}$ Yozgat City Hospital, Cardiology Intensive Care Unit, Yozgat, Turkey. \\ ${ }^{2}$ University of Erciyes, Vocational School of Health Services, Kayseri, Turkey. \\ Correspondence Author: Tugba Onegi \\ E-mail: tugbaoksz_@ @hotmail.com \\ Received: $13.10 .2020 \quad$ Accepted: 28.05 .2021
}

\begin{abstract}
Objective: The aim of this study was to determine sleep quality and fatigue levels of patients who underwent angiography in coronary intensive care unit.

Methods: This study was performed among individuals who underwent angiography in the coronary intensive unit of a City Hospital in the center of a city in Turkey between December 15, 2018 and April 15, 2019 (n:205). Data were obtained using the Patient Identification Form, Richards-Campbell Sleep Scale, Brief Fatigue Inventory.

Results: The mean score of Richard's Campbell Sleep Scale was $46.01 \pm 18.90$ in patients undergoing angiography at the coronary intensive care unit. The mean score of the Brief Fatigue Scale was found to be $4.49 \pm 1.99$. A negative correlation was found between the mean Richard's Campbell Sleep Scale and Brief Fatigue Inventory and its subdimension scores. The fatigue levels were found to be increased as the sleep quality of the patients decreased.

Conclusions: It was determined that patients undergoing coronary angiography had poor sleep quality and high levels of fatigue, and this was caused by several factors. In line with these results, it is recommended to make nursing care plans and consultancy for sleep hygiene and activity planning at regular intervals for individuals at risk.

Keywords: Coronary intensive care, angiography, sleep quality, fatigue, nursing
\end{abstract}

\section{INTRODUCTION}

Coronary artery disease (CAD) is a health problem that occurs as a result of deterioration of myocardial blooe flow due to narrowing or occlusion of coronary arteries with an atherosclerotic plaque. ${ }^{1,2}$ According to the American Heart Association (AHA) information, coronary artery disease has been diagnosed in more than $\mathbf{1 3 . 2}$ million people in the United States resulting in an average annual mortality or myocardial infarction in 1.2 million people. ${ }^{1}$ Coronary heart diseases were found to be the cause of $42.0 \%$ of the deaths among 906 individuals registered and died in 26 years (19902016) according to the Turkish Adult Heart Disease and Risk Factors (TEKHARF) study performed in Turkey. ${ }^{3}$

Coronary artery walls become thicker and atherosclerosis develops in coronary artery disease. ${ }^{1}$ Coronary angiography (CAG) is used to determine the stenosis of the coronary arteries and to plan surgical or medical treatment. In the screening performed using diagnostic procedure codes of the Health Implementation Statement, 260.995 coronary angiographies were performed in 2009, and theumber was increased to 335.113 in 2010. ${ }^{4}$

After coronary angiography, patients face many problems such as sleep problems, fatigue, and limitations in daily living activities. ${ }^{5}$ Not only sleep patterns but also the circadian rhythm is impaired in patients hospitalized in ICU (at least 24 hours) after CAG. ${ }^{6}$ REM period is reported in the literature to constitute only $6.0 \%$ or less of sleep in patients hospitalized in intensive care units. ${ }^{7 .}$ Sleep quality was found to be poor in $68.6 \%$ of the patients diagnosed with coronary artery disease in a study by Vural et al. (2007). ${ }^{9}$ In the study conducted by Gustafsson and Hetta (2001) in coronary intensive care unit, $42.4 \%$ of the patients were found to have problems falling asleep and as a result they felt physically tired. ${ }^{5}$ Insomnia and fatigue was found to increase the level of anxiety in patients who underwent CAG and this was reported to lead to increases blood pressure and heart rates in a study performed by Salamon et al. performed in patients in intensive care units. In addition, anxiety may negatively affect the recovery of the 
patients by decreasing their physical activity and emotional energy levels and even augmenting fatigue and insomnia. ${ }^{10}$

The role and responsibility of a nurse during the process of coronary angiography is counselling as providing information and training of the individual in addition to caregiving. ${ }^{11}$ The nursing care begins with the admission of the patient to the intensive care unit. ${ }^{12}$ Factors such as providing inadequate information of the patiens to be admitted to the intensive care about their disease and treatment, inability to see their relatives, estrangement to the environment and surrounding individuals, to be bedridden, limitation of the movements, stimulations in the intensive unit and anxiety result in problems such as fatigue by disturbing sleep patterns. ${ }^{13,14}$ It is one of the most important responsibilities of the nurses working at the coronary intensive care unit to determine and exclude the physical, environmental and emotional factors that prevent the patients from having a good quality and quantity of sleep, and to provide and maintain a normal sleep process and to relieve the fatigue of the patients. ${ }^{12}$

Sleep problems and fatigue are found to be common in individuals diagnosed to have coronary artery disease in the studies performed. ${ }^{5,15,16}$ No study performed in this country has been encountered on the sleep quality and fatigue levels of patients hospitalized after angiography in the CCU and evaluating the troponin value and the risk factors including the drugs used. This present study is considered to contribute to the literature by extensively evaluating sleep and fatigue level after angiography. Therefore, this study was conducted to determine sleep quality and fatigue level after angiography.

The aim of this study was to determine the sleep quality and fatigue level of patients who underwent angiography in coronary intensive care unit.

The study questions include the following:

1. What is the sleep quality of patients undergoing coronary angiography?

2. What is the level of fatigue in patients undergoing coronary angiography?

3. Is there a relationship between sleep quality and fatigue levels of the patients?

4. What are the sleep quality and fatigue levels of the patients according to the troponin value?

5. What are the sleep quality and fatigue levels according to the drugs used by the patients?

\section{METHODS}

\subsection{Study Design}

A cross-sectional descriptive design was used for the study.

\subsection{Setting, Sample and Data Collection}

The universe of the study was composed of individuals who were admitted to the coronary intensive care unit and underwent angiography between December 12, 2018 and April 15, 2019 at a city hospital in Turkey. A total of 390 patients were admitted to the CCU between these dates. Individuals excluded from the study were 35 due to hearing or vision problems, 50 for being over 75 or under 30 years of age, 12 due to administration of psychiatric drugs that have an effect on sleep and fatigue, 45 due to admission to the intensive care unit at 22:00 hours or presence of a sheath around those hours, 25 due to decision of a bypass procedure after the angiography (myocard infactus). and thus referrence of the patient to another place, and 18 due to transfer to the cardiology service or voluntary discharge on the same day. The research was completed with 205 people. The treatment hours in Coronary Intensive Care Unit are generally between 09:00 in the morning and 21:00 in the evening and after 24:00 the lights are turned off except for the nurse's desk. At $3 \mathrm{am}$, ECG and blood samples are routinely obtained in each patient. If the condition of the patients is appropriate, curtains are drawn during the night hours and care is taken to speak in a low voice. The applications are tried to be performed calmly when needed in emergency conditions and care is taken not to disturb the rest of the patients. No regular sleep hygiene training is provided for the patients during the hospital stay or after the discharge.

Individuals who underwent angiography and included in the sample were with ages between 30 to 75 years and who stayed at least one night in the $\mathrm{CCU}$, were hemodynamically stable, had a pain scale below 3 , had no mechanical ventilation and were not sedated, had a glaskow coma score of 15 and were sufficient to answer the research questions and who provided a written and verbal consent to participate in the study.

Patients who had visual and hearing problems, who were using antihistamines and psychiatric drugs, who had sheath after 22:30 hours, who took medication for sleep and were put into pre-treatment were excluded from the study.

One-to-one face-to-face interviews were conducted about the patient's general condition, history of arrival, and disease. Before bedtime (as of 22:30 hours), the patient's questions were answered within the scope of counseling. During the daytime on the second day, the sleep quality and level of fatigue of the patient concerning the previous night's sleep was evaluated by means of face-to-face interviews for 30 minutes using data collection instruments.

\subsection{Measures}

The data of the research were collected using Patient Identification Form, Richards-Campbell Sleep Scale and Brief Fatigue Inventory. 


\subsubsection{Patient identification form}

This form, which was developed by the researchers by scanning the literature, consists of 2 sections - 17 questions to evaluate the "Socio-Demographic Characteristics" and "Disease Characteristics". ${ }^{17-20}$

1. Socio-demographic characteristics evaluated were age, sex, marital status, level of education, occupation, cigarette smoking and alcohol use and the people living with them.

2. Disease Characteristics evaluated consisted of 9 questions including the presence of previosly diagnosed chronic disease and the diagnosis of the disease, previous $\mathrm{MI}$, the status of using drugs if previous MI was positive, troponin value (highlow), after angiography, and the drugs used and presence of stent implantation.

Figure 1. Reference range of the biochemistry results

\begin{tabular}{|l|l|}
\hline Biochemistry Result & $\begin{array}{l}\text { Reference Range of the Laboratory } \\
\text { Findings }\end{array}$ \\
\hline Troponin (ng/ml)* & $0: 00$ to 2:00 \\
\hline
\end{tabular}

* The results of the City Hospital Central Laboratory were taken into consideration in the evaluation of the laboratory results given in the reference range in Figure 1. Accordingly, the results below the reference range and the reference range were considered as "normal" and results above the reference range as "high". Troponin" values are taken from the patient file.

\subsubsection{Richards-Campbell sleep scale}

Richards C. developed the Richards-Campbell Sleep Scale (RCSS) in $1987 .{ }^{21}$ It is a 6-item scale that assesses the depth of night sleep, the time to fall asleep, the frequency of waking up, the duration of staying awake, the quality of sleep and the noise level in the environment. The first 5 questions are included in the scale and the 6th question is excluded from the scoring. Each item is evaluated by the visual analog scale technique with 5 points increments $(0-5-10-15 . . .-90-95-$ 100 ) on the chart between 0 and 100. A score between " 0 25 " indicates a very poor sleep while a score between "76100 " indicates a very good sleep. The higher the scale score, the better the sleep quality of the patients. The cronbach $\alpha$ value of the scale developed by Richards was found to be 0.82. Turkish adaptation of Richard Campbell sleep scale and evaluation of its reliability and validity was performed by Ozlu and Ozer in 2015. It was decided that this scale could be used in research on the topic in Turkey (Cronbach's alpha 0.91).22 The Cronbach's Alpha value of the scale was found to be 0.93 in this present study.

\subsubsection{Brief fatigue inventory (BFI))}

The Cronbach alpha internal consistency coefficient of the BFI which was developed in 1999 by Mendoza et al. ${ }^{23}$ and was determined to be appropriate for Turkish society by Cinar et al. ${ }^{24}$ was found to be 0.98 . BFI evaluates the severity of fatigue (currently, always, worst) $(1,2,3)$ and the effect of fatigue on daily living activities ( $4 a, 4 b, 4 c, 4 d, 4 e, 4 f)$. Each item of the $\mathrm{BFI}$ consisting of nine items has a value between $0-10$ points. Fatigue severity score is calculated by dividing the total score of items 1, 2 and 3 into 3 and the score of effect of fatigue on living activities is calculating the total score of items $4 a$, $4 b, 4 c, 4 d, 4 e, 4 f$ into 6 . As the score obtained from the scale increases, it is interpreted as that the severity of fatigue and its effect on daily living activities increase. ${ }^{23-25}$ In this present study, fatigue assessment was made based on the total score obtained. In this present study, the cronbach alpha value of the scale was determined as 0.96 .

\subsection{Statistical Analysis}

The data of the study were evaluated by using Statistical Package for Social Sciences (SPSS) (23.0) program. The independent variables of the study were the data on the sociodemographic characteristics of the patient such as age, gender and educational background. Dependent variables of the study were Richard's Campbell Sleep Scale, Brief Fatigue Inventory and its sub-dimensions. The normal distribution of the data was done by Shapiro-Wilk test. Descriptive statistics were used to determine the socio-demographic characteristics. In order to determine the difference between the mean Fatigue and Sleep quality between the groups, t-test was used for independent groups for 2-group comparisons and one-way anova for more than two groups. If a difference was determined as a result of comparisons made in more than two groups, tukey test was performed as post hoc analysis. Pearson correlation analysis was used to determine the results of correlations between Richard's Campbell Sleep Scale, Brief Fatigue Inventory and its subdimensions and age variable. Power analysis was used. In the comparisons, $p<0.05$ was considered statistically significant.

\section{RESULTS}

\subsection{Participant Characteristics and Demographics}

Among the participants, $68.8 \%$ of the individuals were male, the mean age was $58.06 \pm 9.32$ years, $85.9 \%$ were married and $40.0 \%$ were cigarette smokers. In addition, $64.4 \%$ of individuals were found to have chronic diseases. Among the patients, $90.2 \%$ had chest pain, $81.0 \%$ had ECG changes and $73.7 \%$ had high Troponin levels. Some $58.5 \%$ of the individuals were found to be diagnosed to have MI and $77.1 \%$ had never had $\mathrm{MI}$ before. $98.5 \%$ of the patients were using drugs after angiography. $69.8 \%$ were found to use antihypertensives, 94.6\% antithrombolytic drugs, 5.9\% diuretics, 50.2\% lipid lowering drugs, $14.1 \%$ coronary vasodilators and $86.8 \%$ proton pump inhibitors (Table 1).

\subsection{Richards Campbell Sleep Scale and Brief Fatigue Inventory}

Mean RCSS score of the subjects was $46.01 \pm 18.90$. Mean BFI score of the individuals was $4.49 \pm 1.99$, mean score of Fatigue Severity subscale was $4.88 \pm 2.00$ and mean score of Fatigue Impact on Daily Living Activities was $4.29 \pm 2.14$ (Table 2). 
Table 1. Characteristics of the study sample $(n=205)$

\begin{tabular}{|c|c|c|}
\hline Specifications & N & $\%$ \\
\hline \multicolumn{3}{|l|}{ Gender } \\
\hline $\begin{array}{l}\text { Female } \\
\text { Male }\end{array}$ & $\begin{array}{c}64 \\
141\end{array}$ & $\begin{array}{l}31.2 \\
68.8\end{array}$ \\
\hline Age (Year Mean $\pm s s)$ (min-max) & \multicolumn{2}{|c|}{$58.06 \pm 9,32(34.0-75.0)$} \\
\hline \multicolumn{3}{|l|}{ Marital Status } \\
\hline $\begin{array}{l}\text { Married } \\
\text { Single }\end{array}$ & $\begin{array}{c}176 \\
29\end{array}$ & $\begin{array}{l}85.9 \\
14.1\end{array}$ \\
\hline \multicolumn{3}{|l|}{ Status of Cigarette Smoking } \\
\hline \begin{tabular}{|l} 
Positive \\
Negative \\
Quit Smoking \\
\end{tabular} & $\begin{array}{l}82 \\
63 \\
60 \\
\end{array}$ & $\begin{array}{l}40.0 \\
30.7 \\
29.3\end{array}$ \\
\hline \multicolumn{3}{|l|}{ Status of Chronic Disease } \\
\hline $\begin{array}{l}\text { Present } \\
\text { None }\end{array}$ & $\begin{array}{c}132 \\
73\end{array}$ & $\begin{array}{l}64.4 \\
35.6\end{array}$ \\
\hline \multicolumn{3}{|l|}{ Status of Chest Pain } \\
\hline $\begin{array}{l}\text { Present } \\
\text { None }\end{array}$ & $\begin{array}{c}185 \\
20\end{array}$ & $\begin{array}{c}90.2 \\
9.8\end{array}$ \\
\hline \multicolumn{3}{|l|}{ Status of ECG Change } \\
\hline $\begin{array}{l}\text { Present } \\
\text { None }\end{array}$ & $\begin{array}{c}166 \\
39\end{array}$ & $\begin{array}{l}81.0 \\
19.0\end{array}$ \\
\hline \multicolumn{3}{|l|}{ Status of High Troponine Value } \\
\hline $\begin{array}{l}\text { Present } \\
\text { None }\end{array}$ & $\begin{array}{c}151 \\
54\end{array}$ & $\begin{array}{l}73.7 \\
26.3\end{array}$ \\
\hline \multicolumn{3}{|l|}{ Diagnosis } \\
\hline $\begin{array}{l}\text { Chest Pain } \\
\text { Myocardial Infarct (MI) } \\
\text { Atherosclerotic Heart Disease } \\
\end{array}$ & $\begin{array}{c}57 \\
120 \\
28\end{array}$ & $\begin{array}{l}27.8 \\
58.5 \\
13.7 \\
\end{array}$ \\
\hline \multicolumn{3}{|l|}{ Status of Previous Myocardial Infarction } \\
\hline $\begin{array}{l}\text { Previous Myocardial Infarct Positive } \\
\text { No Previous Myocardial Infarct }\end{array}$ & $\begin{array}{c}47 \\
158\end{array}$ & $\begin{array}{l}22.9 \\
77.1\end{array}$ \\
\hline \multicolumn{3}{|l|}{ Status of Medication Use } \\
\hline \begin{tabular}{|l} 
Positive \\
Negative \\
\end{tabular} & $\begin{array}{c}202 \\
3\end{array}$ & $\begin{array}{c}98.5 \\
1.5\end{array}$ \\
\hline \multicolumn{3}{|l|}{ Status of Antihypertensive Drug Use } \\
\hline $\begin{array}{l}\text { Positive } \\
\text { Negative }\end{array}$ & $\begin{array}{c}143 \\
62\end{array}$ & $\begin{array}{l}69.8 \\
30.2\end{array}$ \\
\hline \multicolumn{3}{|l|}{ Status of Antithrombotic Drug Use } \\
\hline \begin{tabular}{|l} 
Positive \\
Negative
\end{tabular} & $\begin{array}{c}194 \\
11 \\
\end{array}$ & $\begin{array}{c}94.6 \\
5.4 \\
\end{array}$ \\
\hline \multicolumn{3}{|l|}{ Status of Diutetic Drug Use } \\
\hline $\begin{array}{l}\text { Positive } \\
\text { Negative }\end{array}$ & $\begin{array}{c}12 \\
193\end{array}$ & $\begin{array}{c}5.9 \\
94.1\end{array}$ \\
\hline \multicolumn{3}{|l|}{ Status of Lipid Lowering Drus Use } \\
\hline $\begin{array}{l}\text { Positive } \\
\text { Negative }\end{array}$ & $\begin{array}{l}103 \\
102\end{array}$ & $\begin{array}{l}50.2 \\
49.8\end{array}$ \\
\hline \multicolumn{3}{|l|}{ Status of Coronary Vasodilator Drug Use } \\
\hline $\begin{array}{l}\text { Positive } \\
\text { Negative }\end{array}$ & $\begin{array}{c}29 \\
176\end{array}$ & $\begin{array}{l}14.1 \\
85.9\end{array}$ \\
\hline \multicolumn{3}{|c|}{ Status of Proton Pump Inhibitor Drug Use } \\
\hline $\begin{array}{l}\text { Positive } \\
\text { Negative }\end{array}$ & $\begin{array}{c}178 \\
27\end{array}$ & $\begin{array}{l}86.8 \\
13.2\end{array}$ \\
\hline
\end{tabular}

Table 2. Mean score of RCSS and BFI and its sub-dimensions of individuals

\begin{tabular}{|l|c|c|c|c|}
\hline Scale & $\boldsymbol{N}$ & $\mathbf{X}+$ SD & Min. & Max. \\
\hline Richard's Campbell Sleep Scale & 205 & $46.01 \pm 18,90$ & 3.33 & 88.33 \\
\hline $\begin{array}{l}\text { Brief Fatigue Inventoryof } \\
\text { Individuals }\end{array}$ & 205 & $4.49 \pm 1.99$ & 0.56 & 9.44 \\
\hline $\begin{array}{l}\text { Severity of Fatigue Sub- } \\
\text { Dimension Score }\end{array}$ & 205 & $4.88 \pm 2.00$ & 0.67 & 9.33 \\
\hline $\begin{array}{l}\text { Sub-Dimension of Effect of } \\
\text { Fatigue on Daily Life Activities }\end{array}$ & 205 & $4.29 \pm 2.14$ & 0.33 & 9.50 \\
\hline
\end{tabular}

\subsection{Comparison of Sub-dimensions of Scales (Brief Fatigue Inventory) According to Descriptive Characteristics of Individuals}

There was no significant difference between mean sleep and fatigue scores according to sociodemographic characteristics $(p>0.05)$. Sleep quality was found to be worse in patients with chronic disease $(p<0.05)$. The mean score of BFI Fatigue Severity Sub-Scale was found to be significantly higher in individuals with chronic disease $(p<0.05)$. There was no statistically significant difference between the mean scores of RCSS according to presence of HT in the participants ( $p>$ 0.05 ). The mean score of BFI Fatigue Severity Sub-Scale was found to be significantly higher in subjects with $\mathrm{HT}(\mathrm{p}<0.05)$. There was no statistically significant difference between the mean scores of RCSS according to the ECG change status of the participants $(p>0.05)$. The mean Fatigue Severity Subdimension score was higher in subjects with ECG changes $(p<0.05)$. According to the nausea-vomiting status of the individuals, there was a significant difference in the effect subscale scores of fatigue on daily living activities. It was found that the mean RCSS score was significantly lower in individuals with high troponin levels and the total score of BFI and the Fatigue Severity Subdimension Score was higher in individuals with high troponin levels $(p<0.05)$. There was no statistically significant difference between the mean scores of RCSS according to the diagnosis of the individuals ( $p>$ 0.05). The total and subdimension BFI scores of the patients undergoing angiography for $\mathrm{Ml}$ were significantly higher compared to the remaining group $(p<0.05)$. There was no significant difference between the mean scores of RCSS according to stent implantation status after angiography ( $p>0.05$ ). However, STE and subdimension scores were found to be higher in patients with stent implantation after angiography compared to the group without stents $(p<0.05)$. There was no statistically significant difference between the mean scores of RCSS according to the antihypertensive and coronary vasodilator drug use of the individuals. However, scores of $\mathrm{BFI}$ and its sub-scales were found to be higher in patients who used antihypertensive drugs compared to those who used no antihypertensives. BFI and sub-scale scores were found to be lower in patients who used coronary vasodilators compared to those who used no coronary vasodilators $(p<0.05)$ (Table 3$)$. 
Table 3. Comparison of sub-dimensions of the scales by descriptive properties of the individuals

\begin{tabular}{|c|c|c|c|c|c|}
\hline & $\mathrm{n}$ & $\begin{array}{l}\text { Richard's Campbell } \\
\text { Sleep Scale }\end{array}$ & $\begin{array}{c}\text { Brief Fatigue } \\
\text { Inventoryof Individuals }\end{array}$ & $\begin{array}{l}\text { Severity of Fatigue Sub- } \\
\text { Dimension Score }\end{array}$ & $\begin{array}{l}\text { Sub-Dimension of } \\
\text { Effect of Fatigue on } \\
\text { Daily Life Activities }\end{array}$ \\
\hline $\begin{array}{l}\text { Status of Chronic } \\
\text { Disease }\end{array}$ & & $X+S D$ & $X+S D$ & $X+S D$ & $X+S D$ \\
\hline Present & 132 & $43.14 \pm 18,83$ & $4.62 \pm 2,06$ & $5.09 \pm 2,06$ & $4.39 \pm 2,20$ \\
\hline \multirow[t]{2}{*}{ None } & 73 & $51.22 \pm 18.02$ & $4.26 \pm 1.87$ & $4.51 \pm 1.87$ & $4.14 \pm 2.03$ \\
\hline & & $p=0.003^{*}$ & $p=0.224$ & $p=0.049^{*}$ & $p=0.437$ \\
\hline \multicolumn{6}{|l|}{ Status of HT } \\
\hline Present & 81 & $44.00 \pm 17,81$ & $4.78 \pm 2,00$ & $5.33 \pm 2,03$ & $4.50 \pm 2,15$ \\
\hline \multirow[t]{2}{*}{ None } & 123 & $47.39 \pm 19,61$ & $4.30 \pm 1,98$ & $4.58 \pm 1,95$ & $4.16 \pm 2,14$ \\
\hline & & $p=0.213$ & $p=0.094$ & $p=0.009^{*}$ & $p=0.261$ \\
\hline \multicolumn{6}{|l|}{ Status of ECG Change } \\
\hline Present & 166 & $45.41 \pm 18,95$ & $4.62 \pm 1,97$ & $5.03 \pm 1,96$ & $4.42 \pm 2,13$ \\
\hline \multirow[t]{2}{*}{ None } & 39 & $48,59+18,76$ & $3.94 \pm 2,04$ & $4.27 \pm 2,10$ & $3.77 \pm 2,14$ \\
\hline & & $p=0.346$ & $p=0.053$ & $p=0.032^{*}$ & $p=0.261$ \\
\hline \multicolumn{6}{|l|}{$\begin{array}{l}\text { Status of Nausea/ } \\
\text { Vomiting }\end{array}$} \\
\hline Present & 48 & $44.31 \pm 19.09$ & $4.98 \pm 2.03$ & $5.26 \pm 1.87$ & $4.84 \pm 2.30$ \\
\hline \multirow[t]{2}{*}{ None } & 157 & $46.54 \pm 18.88$ & $4.34 \pm 1.97$ & $4.77 \pm 2.04$ & $4.13 \pm 2.07$ \\
\hline & & $p=0.476$ & $p=0.054$ & $p=0.141$ & $p=0.045^{*}$ \\
\hline \multicolumn{6}{|l|}{$\begin{array}{l}\text { Status of High } \\
\text { Troponine Value }\end{array}$} \\
\hline Present & 151 & $44.46 \pm 18.04$ & $4.68 \pm 1.96$ & $5.13 \pm 2.00$ & $4.46 \pm 2.08$ \\
\hline \multirow[t]{2}{*}{ None } & 54 & $50.36 \pm 18.57$ & $3.96 \pm 2.03$ & $4.18 \pm 1.87$ & $3.85 \pm 2.26$ \\
\hline & & $\mathrm{p}=0.049 *$ & $\mathrm{p}=0.022^{*}$ & $p=0.002^{*}$ & $p=0.072$ \\
\hline \multicolumn{6}{|l|}{ Diagnosis } \\
\hline Chest Pain & 57 & $48.18 \pm 19.72$ & $3.91 \pm 1.93$ & $4.42 \pm 2.10$ & $3.67 \pm 1.98$ \\
\hline Myocardial Infarct (MI) & 120 & $43.82 \pm 18.65$ & $4.98 \pm 1.94$ & $5.32 \pm 1.93$ & $4.80 \pm 2.12$ \\
\hline \multirow[t]{2}{*}{$\begin{array}{l}\text { Atherosclerotic Heart } \\
\text { Disease }\end{array}$} & 28 & $51.01 \pm 17.40$ & $3.59 \pm 1.75$ & $3.95 \pm 1.68$ & $3.42 \pm 1.96$ \\
\hline & & $p=0.115$ & $p<0.001^{*}$ & $p=0.001^{*}$ & $p<0.001^{*}$ \\
\hline \multicolumn{6}{|l|}{$\begin{array}{l}\text { Status of Stent } \\
\text { Implantation after } \\
\text { Angiography }\end{array}$} \\
\hline Stent Implanted & 151 & $45.03 \pm 18.49$ & $4.76 \pm 1.95$ & $5.16 \pm 1.96$ & $4.56 \pm 2.09$ \\
\hline \multirow[t]{2}{*}{ No Stent Implanted } & 54 & $48.77 \pm 19.93$ & $3.74 \pm 1.96$ & $4.11 \pm 1.96$ & $3.56 \pm 2.13$ \\
\hline & & $p=0.214$ & $p=0.001^{*}$ & $p=0.001^{*}$ & $p=0,003^{*}$ \\
\hline \multicolumn{6}{|l|}{$\begin{array}{l}\text { Status of } \\
\text { Antihypertensive Drug } \\
\text { Use }\end{array}$} \\
\hline Present & 143 & $45.00 \pm 17.83$ & $4.78 \pm 2,00$ & $5.21 \pm 2.02$ & $4.55 \pm 2.13$ \\
\hline \multirow[t]{2}{*}{ None } & 62 & $48.36 \pm 21.16$ & $3.84 \pm 1.84$ & $4.10 \pm 1.75$ & $3.71 \pm 2.06$ \\
\hline & & $p=0.244$ & $p=0.002^{*}$ & $p<0.001^{*}$ & $p=0.009^{*}$ \\
\hline \multicolumn{6}{|l|}{$\begin{array}{l}\text { Status of Coronary } \\
\text { Vasodilator Use }\end{array}$} \\
\hline Present & 29 & $51.74 \pm 18.54$ & $3.52 \pm 1.86$ & $3.86 \pm 2.03$ & $3.34 \pm 1.95$ \\
\hline \multirow[t]{2}{*}{ None } & 176 & $45.07 \pm 18.85$ & $4.65 \pm 1.98$ & $5.05 \pm 1.96$ & $4.56 \pm 2.13$ \\
\hline & & $p=0.078$ & $p=0.004^{*}$ & $p=0.003 *$ & $\mathrm{p}=0.009 *$ \\
\hline
\end{tabular}

*Student $t$ test and One way Anova.

\subsection{Bivariate Analysis}

A negative and highy significant correlation was found between mean RCSS and BFI and its subscale scores ( $p$ $<0.05)$. A highly significant and positive correlation was found between the mean total BFI score and mean Severity of Fatigue sub-dimension and Effect on Daily Living Activities Sub-dimension. There was a very weak and positive correlation between age variable and mean Fatigue Severity Subscale score $(p<0.05)$ (Table 4). 
Table 4. Evaluation of the correlations between RCSS, BFI and its sub-dimensions and age of the individuals

\begin{tabular}{|c|c|c|c|c|c|}
\hline $\begin{array}{l}\text { Correlation } \\
\text { Test Results } \\
* * *\end{array}$ & $\begin{array}{c}\text { Mean } \\
\text { Richard's } \\
\text { Campbell } \\
\text { Sleep } \\
\text { Scale } \\
\text { Points }\end{array}$ & $\begin{array}{l}\text { Mean } \\
\text { Brief } \\
\text { Fatigue } \\
\text { Inventory } \\
\text { Points }\end{array}$ & $\begin{array}{c}\text { Mean } \\
\text { Severity } \\
\text { of Fatigue } \\
\text { Sub- } \\
\text { Dimension } \\
\text { Points }\end{array}$ & $\begin{array}{l}\text { Mean Effect } \\
\text { of Fatigur } \\
\text { on Daily Life } \\
\text { Activities } \\
\text { Sub- } \\
\text { Dimension } \\
\text { Points }\end{array}$ & Age \\
\hline $\begin{array}{l}\text { Mean } \\
\text { Richard's } \\
\text { Campbell } \\
\text { Sleep Scale } \\
\text { Points }\end{array}$ & - & - & - & - & - \\
\hline $\begin{array}{l}\text { Mean Brief } \\
\text { Fatigue } \\
\text { Inventory } \\
\text { Points }\end{array}$ & $-0.302^{* *}$ & - & - & - & - \\
\hline $\begin{array}{l}\text { Mean } \\
\text { Severity of } \\
\text { Fatigue Sub- } \\
\text { Dimension } \\
\text { Points }\end{array}$ & $-0.330^{* *}$ & $0.897^{* *}$ & - & - & - \\
\hline $\begin{array}{l}\text { Mean Effect } \\
\text { of Fatigur } \\
\text { on Daily Life } \\
\text { Activities } \\
\text { Sub- } \\
\text { Dimension } \\
\text { Points }\end{array}$ & $-0.268^{* *}$ & $0.987^{* *}$ & $0.786^{* *}$ & - & - \\
\hline Age & -0.081 & 0.110 & $0.160^{*}$ & 0.079 & - \\
\hline
\end{tabular}

***Pearson correlation analysis was performed.

\section{DISCUSSION}

Sleep is a biological need and one of the most important predictors of physical and mental health. Exposure of patients to sound, noise, light and many procedures in the intensive care unit increases night wakes, in which case their deep sleep is interrupted and have inadequate sleep, decreased energy levels and increased fatigue. ${ }^{13,14}$ In this present study, the mean RCSS and BFI scores in patients who underwent angiography and admitted to the coronary intensive care unit were found to be in a moderate level and fatigue was found to be increased as sleep quality was decreased. Higgins et al. (2000) reported that patients experienced severe anxiety, sleep disturbances, fatigue and sensation of low energy after angioplasty. ${ }^{26}$ In a study conducted by Gustafsson and Hetta (2001) in a coronary intensive care unit, $42.4 \%$ of the patients stated that they had problems in maintaining sleep and felt physical fatigue due to sleep problems. ${ }^{5}$ When the literature is evaluated, fatigue was emphasized to increase due to deterioration in cardiac functions and decrease in daily living activities of the individual. ${ }^{27,28}$ Fatigue was suggested to occur secondary to inadequate rest after the procedure, cardiac problems, disruption of nutrition, $\mathrm{O}_{2}$ requirement and sleep pattern of the individual.
The presence of chronic diseases in patients hospitalized in coronary intensive care unit is one of the important factors in the development of sleep problems. ${ }^{29}$ Our research findings, similar with the literature, pointed out that individuals with chronic disease had poor sleep quality and higher fatigue levels compared to those without chronic diseases. This finding shows that quality of sleep is affected and fatigue level is increased in individuals with chronic diseases due to more sleep breaks for administration of medication / treatment in addition to the symptoms of the disease itself. Inadequate sleep creates a vicious circle after a certain period of time, leading to increased sensitivity to pain, disgust and distractibility. ${ }^{30}$

In the literature, hypertension and diabetes are the leading risk factors for coronary artery disease. ${ }^{31}$ In this present study, patients with $\mathrm{HT}$ and on antihypertensives were found to have more fatigue. Angiotensin-containing enzyme inhibitors used in the treatment of hypertension may adversely affect sleep, leading to impaired performance. ${ }^{32}$ Similar to our study, Cho, Hyoung-Park (2004) reported in their study that individuals with hypertension had higher levels of fatigue. ${ }^{33}$ Increased sympathetic nervous system activity in hypertension leads to overproduction of vasoconstrictors such as endothelin and thromboxane and sodium retaining hormones, inappropriate renin secretion and reduced production of vasodilating agents such as nitric oxide and prostaglandins. These physiological changes may cause fatigue, headache, palpitations, dyspnea and tiredness in individuals. ${ }^{32}$

In this present study, individuals with ECG changes were found to have higher levels of fatigue. In the literature, the presence of diffuse ST segment elevation on ECG has been shown to cause unexplained fatigue in individuals. Individuals with a high troponine level were determmined to have a worse sleep quality and increased fatigue compared to patients without a high troponin value in this present study. Troponin and CK-MB levels are the two most important markers in patients undergoing MI. Elevated troponin levels and ECG changes suggest that patients have more cardiac damage after an MI. ${ }^{34}$ As a result of the cardiac damage, fatigue and insomnia may be considered as an expected result.

Individuals with nausea and vomiting were found in this present study to have higher Fatigue Daily Life Activity scores. Nausea and vomiting complaint of the patients result in fatigue, limitation of daily living activities and decreased motivation by causing energy loss in time and increased need to rest. ${ }^{35}$ The results of this present study is parallel to the literature findings.

When the scale scores were compared according to the diagnoses of the individuals, the sleep quality of the patients with MI was found $t$ be decreased and fatigue level was found to be increased. Impairment of sleep quality is especially common in patients with acute $\mathrm{Ml}$ and it adversely affects the healing process. According to the results of many studies and guidelines used, the most common symptoms in patients with coronary artery disease are sleep problems, fatigue, chest pain, sweating, weakness and respiratory distress. ${ }^{36,37}$ 
It should be kept in mind that individuals who underwent coronary angiography and were admitted to intensive care units due to an MI may experience fatigue and impaired sleep quality, and nursing care should be planned accordingly.

In this present study, sleep quality was worse and level of fatigue was higher in patients with stent implantation, although not significant. Currently, stent application, one of the interventional treatments has become a routine and safe procedure in patients with an $\mathrm{Ml}$ and in appropriate indications. It has been shown in the literature that patients who underwent coronary angioplasty and intra-coronary stenting had problems such as chest pain, palpitation and difficulty in breathing in the post-procedure period and presented to the hospital with these problems. ${ }^{38,39}$ Accordingly, it is thought that long-term lying on the back in an intensive care, stent implantation in addition to angiography and environmental factors affect patients' sleep quality.

In addition, patients using coronary vasodilators were found to have higher sleep quality and less fatigue in this present study. Drugs in this group reduce the myocardial oxygen demand by rapidly expanding the coronary arteries and rapidly eliminating the symptoms. ${ }^{40}$ Thus, it can be considered that coronary vasodilators provide better sleep and decrease fatigue in patients with coronary artery disease by alleviating their symptoms.

In our study, it was found that there was a negative, if not significant, relationship between age variable and sleep quality. It was determined that sleep quality was decreased and severity of fatigue was increased with age. In the literature, it is reported that age is one of the leading causes of changes in sleep duration and habits, and that the duration of sleep decreases by one hour for every 10 years starting from the age of 50 years. As the age advances, patients are expected to experience more physical fatigue. It may cause fatigue and decrease the sleep quality in the environment such as intensive care with age. The literature supports the results of our findings. ${ }^{19}$

Many factors impair sleep quality and increase fatigue. Providing nursing care to improve sleep quality of patients who underwent angiography is considered to facilitate the patients' coping capacity with fatigue and thus improve sleep quality.

\section{CONCLUSION}

In this present study, the sleep quality of the patients was found to be poor and fatigue levels were found to be high. Presence of chronic diseases and hypertension, ECG changes, diagnosis of $\mathrm{MI}$, post-angiography stent implantation, antihypertensive use and high troponin levels decrease the sleep quality of the patients and increase their fatigue levels. The sleep quality of the patients was found to be decreased with increasing age, and fatigue level was found to be increased with decreasing sleep quality. According to the results; as fatigue and sleep quality may change over time, it is recommended to collect data at regular intervals in individuals at risk and to plan nursing interventions and consultancy on the factors causing these problems.

\subsection{Limitations}

This study had a few limitations that need to be acknowledged. Troponin values were entered as low or high, numerical values could not be reached. While examining the sleep phenomenon which is a complex structure, the severity of the underlying disease, as well as the sleeping habits of the patients in their normal lives, and their awakening cycles vary daily and time to time. This is considered among the uncontrollable factors of the study. A single day of follow-up was possible since the patients were rapidly discharged. Therefore, no intervention was performed in patients other than clinical pain treatment protocol when they had pain in late night hours. No measures for restrictions for pain was taken. The study was terminated in cases such as increased severity of illness, inability to speak due to pain or discomfort, patients's withdrawal from the research on his/her own decision, and transfer of the patient to another clinic from the CCU at the night of the application.

Ethics Committee Approval: Ethics committee approval (2017-KAEK-189_2018.12.12_01) from the Bozok University Ethical Evaluation Commission, written permission from the institution where the research was planned to be conducted and informed consents from the individuals participating in the study on willingness and voluntary basis were obtained after the aim of the study was explained.

\section{Acknowledgements}

The authors sincerely thank all the participants in this study and the nurses for helping with data processing.

\section{Funding}

There was no financial support.

\section{Conflict of Interest}

The authors declare no potential conflict of interest with respect to the research, authorship, and/or publication of this article.

\section{REFERENCES}

[1] Gökçe E, Arslan S. Possible effect of video and written education on anxiety of patients undergoing coronary angiography. J Perianesth Nurs 2019; 34(2): 281-288.

[2] Dobber J, Latour C, Snaterse M, et al. Developing nurses' skills in motivational interviewing to promote a healthy lifestyle in patients with coronary artery disease. Eur J Cardiovasc Nurs 2019; 18.1: 28-37.

[3] Turkey Adult Risk Factor Study 2017. [Accessed April 23, 2021]. https://file.tkd.org.tr/PDFs/TEKHARF-2017.pdf.

[4] Balbay Y, Bener S, Kaygusuz, T, et al. Coronary revascularization (Examples from the world and Turkey). Arch Turk Soc Cardiol 2014;42(3):245-252. 
[5] Gustafsson UM, Hetta JE. Fragmented sleep and tiredness in males and females one year after percutaneous transluminal coronary angioplasty (PTCA). J Adv Nurs 2001;34(2):203-211.

[6] Boyko Y, Jennum P, Nikolic M, Holst R, Oerding H, Toft P. Sleep in intensive care unit: the role of environment. J Crit Care 2017; 37, 99-105.

[7] Younis MB, Hayajneh F, Batiha AM. Measurement and nonpharmacologic management of sleep disturbance in the intensive care units: A literature review. Crit Care Nurs Q 2019;42(1): 75-80.

[8] Bihari S, Doug McEvoy R, Matheson E, Kim S, Woodman RJ, Bersten AD. Factors affecting sleep quality of patients in intensive care unit. J Clin Sleep Med 2012; 8(3): 301-307.

[9] Vural N, Karakuş H, Türkan K, et al. Sleep quality in individuals with cardiovascular disease. VII. National Nursing Students Congress. İstanbul. 2007.

[10] Salamon E, Kim M, Beaulieu J, et al. Sound therapy induced relaxation: down regulating stress processes and pathologies. Med Sci Monit 2003;9(5):96-101.

[11] Kasapoğlu ES, Enç N. A Guide for Coronary Artery Patients. Turk J Cardiovasc Nurs 2017;8(15):1-7

[12] Yıldız TF, Tel AH. The affect of sleep hygiene education of patients' sleep quality after coronary intensive care. Journal of The Turkish Society of Critical Care Nurses 2013;17(1):1-7.

[13] Dickens C, Cherrington, A, Mcgowan L. Depression and healthrelated quality of life in people with coronary heart disease: a systematic review. Eur J Cardiovasc Nurs 2012;11(3): 265-275.

[14] Pagnucci N, Tolotti A, Cadorin L, Valcarenghi D, Forfori F. Promoting nighttime sleep in the intensive care unit: alternative strategies in nursing. Intensive Crit Care Nurs 2019; 51: 73-81.

[15] Daghlas I, Dashti HS, Lane J, Aragam KG, Rutter MK, Saxena R, Vetter, C. Sleep duration and myocardial infarction. J Am Coll Cardiol 2019; 74(10): 1304-1314.

[16] Song C, Zhang R, Liao J, Fu R, et al. Sleep quality and risk of coronary heart disease-a prospective cohort study from the English longitudinal study of ageing. Aging (Albany NY) 2020; 12(24); 25005.

[17] Mashayekhi F, Arab M, Pilevarzadeh M, et al. The effect of eye mask on sleep quality in patients of coronary care unit. Sleep Sci 2013;6(3):108-111.

[18] Jones C, Dawson D. Eye masks and earplugs improve patient's perception of sleep. Nurs Crit Care 2012;17(5):247-54.

[19] Tenekeci EG, Kara B. The relationship between sleep quality and fatigue in patients with myocardial infarction. Gülhane Med J 2016;58:366-372.

[20] Rejeh N, Heravi-Karimooi M, Tadrisi SD, Jahani A, Vaismoradi $\mathrm{M}$, Jordan $\mathrm{S}$. The impact of listening to pleasant natural sounds on anxiety and physiologic parameters in patients undergoing coronary angiography: a pragmatic quasi-randomizedcontrolled trial. Complement Ther Clin Pract 2016; 25; 42-51.

[21] Richards K. Techniques for measurement of sleep in critical care. Focus Crit Care. 1987;14:34-40.

[22] Özlü ZK, Özer N. Richard-Campbell Sleep Questionnaire Validity and Reliability Study. J Turk Sleep Med 2015; 2:29-32
[23] Mendoza TR, Wang XS, Cleeland CS, Morrissey M, Johnson BA, Wendt JK, et al. The rapid assessment of atigue severity in cancer patients: use of the Brief Fatigue Inventory. Cancer 1999; 85 (5): 1186-1196.

[24] Çınar S, Sarsmaz N, Mentes AO. Can hemodialysis cause acute fatigue syndrome? Nursing Forum 2000; 3:28-33.

[25] Ceyhan Ö, Taşcı S, Elmalı F, et al. The effect of acupressure on cardiac rhythm and heart rate among patients with atrial fibrillation: the relationship between heart rate and fatigue. Altern Ther Health Med 2019;25(1):12-19.

[26] Higgins M, Dunn S, Theobald K. The patients perception of recovery after coronary angioplasty, Aust Crit Care 2000;13(3):83-8.

[27] Frishman WH, Beravol P, Carosella C. Alternative and complementary medicine for preventing and treating cardiovascular disease. Dis Mon 2009;55:121-192.

[28] Newland PK, Lunsford V, Flach A. The interaction of fatigue, physical activity, and health-related quality of life in adults with multiple sclerosis (MS) and cardiovascular disease (CVD). Appl Nurs Res 2017; 33, 49-53.

[29] Cicek HS, Armutcu B, Dizer B, Yava A, Tosun N, Celik, T. Sleep quality of patients hospitalized in the coronary intensive care unit and the affecting factors. Int J Caring Sci 2014; 7(1): 324.

[30] Zaidel C, Musich S, Karl J, Kraemer S, Yeh CS. Psychosocial factors associated with sleep quality and duration among older adults with chronic pain. Popul Health Manag 2021; 24(1): 101-109.

[31] Uçar A, Arslan S. The cardiovascular disease risk factors knowledge level of the adults living in a family health center region. Turk J Cardiovasc Nurs 2017;8(17):121-130.

[32] Story L. Cardiovascular functions. Ovayolu Ö, Ovayolu N. (Ed) A practical approach to pathophysiology (2. Printing) In (69113). Çukurova Publication 2016.

[33] Cho G, Park H. Effects of 6-week foot reflexology on the blood pressure and fatigue in elderly patients with hypertension. J Korean Acad Nurs 2004;11(2):138.

[34] Badır A. Coronary artery diseases. Care in Internal and Surgical Diseases. (3. Printing) In: 431-432. Ankara: Akademisyen Publication. 2014.

[35] Aslan Ö, Vural H, Kömürcü Ş, et al. Effect of education on chemotherapy symptoms in cancer patients receiving chemotherapy. Cumhuriyet University School of Nursing Journal. 2006;10(1).

[36] Moore SM. Effects of interventions to promote recovery in coronary artery bypass surgical patients. Journal of Cardiovascular Nursing 1997;12(1):59-71.

[37] Williams MC, Hunter A, Shah A, et al. Symptoms and quality of life in patients with suspected angina undergoing CT coronary angiography: a randomised controlled trial. Heart 2017;103(13): 995-1001.

[38] Mehrpoya A, Jalali R, Jalali A, Namdari M. Patient experiences of living with coronary stent. J Vasc Nurs 2018; 36(4); 181-185.

[39] Özen TA, Çelik ŞS. Care of the patıents who undergo the coronary angıoplasty and intra coronary stentıng. Journal Anatolia of Nursing and Health Sciences 2010;13:2.

[40] Ministry of Health. Health care, drugs effective on cadiovascular abd respratory systems. Ankara: Ministry of Health. 2017. 